\title{
Combining Fulvestrant with Low-Dose Capecitabine is Effective and Tolerable in Woman with Metastatic Breast Cancer
}

\author{
Maki Nakai ${ }^{1}$, Hiroyuki Takei ${ }^{1}$, Keiko Yanagihara ${ }^{1}$, \\ Koji Yamashita ${ }^{1}$ and Eiji Uchida ${ }^{2}$ \\ ${ }^{1}$ Department of Breast Surgery, Nippon Medical School, Tokyo, Japan \\ ${ }^{2}$ Department of Gastrointestinal and Hepato-Biliary-Pancreatic Surgery, Nippon Medical School, Tokyo, Japan
}

\begin{abstract}
Although the use of endocrine therapy in combination with intravenous chemotherapy has not been standardized, the combination of fulvestrant and chemotherapy may be promising. A 62-year-old woman came to our hospital's outpatient clinic with extensive ascites. Approximately 10 years earlier, she had undergone mastectomy and sentinel lymph node biopsy. Pathologically invasive lobular carcinoma, with a maximum diameter of $28 \mathrm{~mm}$, had been diagnosed in the left breast. The cancer had a histological grade of 2 , was positive for estrogen receptor ( $95 \%$ or more positive cells), and was negative for both progesterone receptor (less than $1 \%$ positive cells) and human epidermal growth factor receptor 2. For 5 years the patient underwent adjuvant endocrine therapy with tamoxifen and then with anastrozole. Four years 2 months after adjuvant endocrine therapy had been completed, she felt abdominal distention, and her symptoms gradually worsened. A series of intensive examinations indicated that the invasive lobular carcinoma had metastasized to the peritoneum, pleura, uterus, and bone. Aromatase inhibitor was administered as a first-line therapy for the metastatic disease and was accompanied by denosumab injected every 28 days. For 2 months after the start of treatment with anastrozole, the ascites did not decrease and tumor markers increased. Because anastrozole had not been effective, fulvestrant $(500 \mathrm{mg})$ and low-dose capecitabine $(500 \mathrm{mg})$ were administered for the first 21 days of a 28-day cycle; this regimen had been shown by a phase 2 trial to be effective and tolerable in patients with metastatic breast cancer. The patient felt an improvement in abdominal distention, and the tumor markers decreased 2 weeks after the start of this combination therapy. By 10 months after the start of the combined therapy the ascites had decreased and pleural effusion had completely disappeared. The uterine wall became thinner, and the endometrial cavity became smaller. Tumor markers continued decreasing. No adverse events were observed. The combination of fulvestrant and low-dose capecitabine is promising because of its efficacy and tolerability for the treatment of patients with estrogen receptorpositive, human epidermal growth factor receptor 2-negative metastatic breast cancer.
\end{abstract}

(J Nippon Med Sch 2016; 83: 81-86)

Key words: fulvestrant, capecitabine, metastatic breast cancer

\section{Introduction}

Fulvestrant is a selective estrogen receptor (ER) downregulator, a so-called "pure antiestrogen," that decreases ER expression with no agonistic effects ${ }^{1,2}$. The expression of ER is also affected by tamoxifen, a selective ER modulator that acts as a partial agonist ${ }^{1}$. Although tamoxifen is effective both in premenopausal and postmenopausal women, fulvestrant is effective only in postmenopausal women ${ }^{3}$. Although fulvestrant has been used at a dose of $250 \mathrm{mg}$, at a dose of $500 \mathrm{mg}$ fulvestrant has been shown to be more effective but no more toxic ${ }^{4,5}$. Currently, the standard administration of fulvestrant is a 500-mg intramuscular injection on days 1, 15, and 29 and every 28 days thereafter.

Correspondence to Maki Nakai, Department of Breast Surgery, Nippon Medical School, 1-1-5 Sendagi, Bunkyo-ku, Tokyo 1138603, Japan

E-mail: n-maki@nms.ac.jp

Journal Website (http://www.nms.ac.jp/jnms/) 
The concurrent administration of tamoxifen and intravenous chemotherapy is no longer performed because synergistic efficacy was not demonstrated ${ }^{6}$. However, an oral fluorouracil prodrug, UFT (uracil and tegafur), has been used in combination with tamoxifen in adjuvant trials in Japan for patients with node-negative breast cancer ${ }^{6}$. In women with ER-positive breast cancer, the combination of UFT and tamoxifen seemed to yield better overall survivals than did each drug alone ${ }^{7}$. Currently, another oral fluorouracil prodrug, TS-1 (tegafur/gimeracil/oteracil potassium), is being investigated in a phase 3 study in Japan to determine whether its addition helps standard adjuvant endocrine therapy to inhibit recurrences in women with ER-positive, human epidermal growth factor receptor 2 (HER2)-negative breast cancer (University Hospital Medical Information Network trial number, 000003969).

In an in vitro study, fulvestrant had a synergistic effect with doxorubicin, paclitaxel, docetaxel, vinorelbine, and fluorouracil; however, tamoxifen did not have such an effect $^{8}$. Fulvestrant itself is a fully active drug that would not be expected to cause clinically significant drug interactions through the inhibition of cytochrome P450 (CYP)mediated metabolism of co-administered agents ${ }^{9}$. Therefore, a concurrently administered drug is not likely to affect the safety or efficacy of fulvestrant ${ }^{9}$. However, tamoxifen is activated after it is metabolized to endoxifen, and its metabolic potency ranges widely due to gene polymorphism CYP2D $6^{10}$. On the basis of these properties, fulvestrant might be a better choice than tamoxifen for use in combination with chemotherapy.

The efficacy and tolerability of the combination of fulvestrant and chemotherapy have been analyzed in only a single prospective trial. In a phase 2 trial, low doses of $1,500 \mathrm{mg}$ (body weight $<80 \mathrm{~kg}$ ) or $2,000 \mathrm{mg}$ of capecitabine were used in combination with a low dose (250 $\mathrm{mg}$ ) of fulvestrant in 41 postmenopausal women with hormone receptor-positive, HER2-negative metastatic breast cancer ${ }^{11}$. The median time to progression (TTP) was 26.9 months, and the clinical benefit rate was $58.5 \%{ }^{11}$. Accordingly, the combination of fulvestrant and capecitabine is a promising treatment for women with ER-positive, HER2-negative metastatic breast cancer.

We report a case of metastatic breast cancer in which combination treatment with fulvestrant and low-dose capecitabine was effective and tolerable.

\section{Case}

A 62-year-old woman with extensive ascites came to our outpatient clinic to consult about whether the ascites was a symptom of recurrent breast cancer. Nine years 10 months earlier, the patient had undergone breastconserving surgery and sentinel lymph node biopsy. One month later she underwent an additional total mastectomy because of positive surgical margins. Pathologically invasive lobular carcinoma, with a maximum diameter of $28 \mathrm{~mm}$, was diagnosed in the left breast. The carcinoma had a histological grade of 2, was positive for ER ( $95 \%$ or more positive cells), and was negative for both progesterone receptor (less than 1\% positive cells) and HER2 (HercepTest $^{\circledR}$, score 0$)$. The patient received tamoxifen for 2 years 9 months and then received anastrozole for 2 years 3 months to receive adjuvant endocrine therapy for a total of 5 years. Each year after surgery she underwent an annual check-up including palpation, mammography, and ultrasonography. Six months ago, a check-up revealed no abnormal locoregional findings. During the same time period, 4 years 2 months after adjuvant endocrine therapy had been completed, she felt abdominal distention, the symptoms of which gradually worsened.

Three months ago, while the patient consulted a physician in a hospital near her home, extensive ascites was diagnosed. She underwent a series of intensive examinations under hospitalization in our hospital's department of internal medicine. Computed tomography (CT) revealed extensive ascites (Fig. 1a) and minimal pleural effusion. The uterine wall was thickened, and the endometrial cavity contained a nonenhanced lesion (Fig. 1 b). There were no abnormal findings in the liver, kidneys, adrenal glands, ovaries, or the lymph nodes of the peritoneal cavity. Magnetic resonance imaging of the pelvis revealed thickening of the myometrium and a fluid collection in the endometrial cavity. Diffusion-weighted images showed thickening of the peritoneum. The bone marrow of the pelvis was irregularly occupied by tumorlike infiltrations. Scintigraphy showed multiple metastases to the vertebrae, pelvic bones, femora, and humeri. Endoscopy had no abnormal findings in the esophagus, stomach, colon, or rectum.

When aspirated the ascites fluid was serous-bloody. Cytologic examination of the ascites fluid identified atypical cells; however, no definitive diagnosis was made. Cytologic examination of the endometrium, cervix, and vagina was negative. The concentrations of the tumor markers carcinoembryonic antigen (CEA), carbohydrate antigen (CA) 15-3, National Cancer CenterStomach-439 (NCC-ST-439), and CA12-5 were $14.2 \mathrm{ng} /$ $\mathrm{mL}, 66.1 \mathrm{U} / \mathrm{mL},>5,000 \mathrm{U} / \mathrm{mL}$, and $265.3 \mathrm{U} / \mathrm{mL}$, respec- 

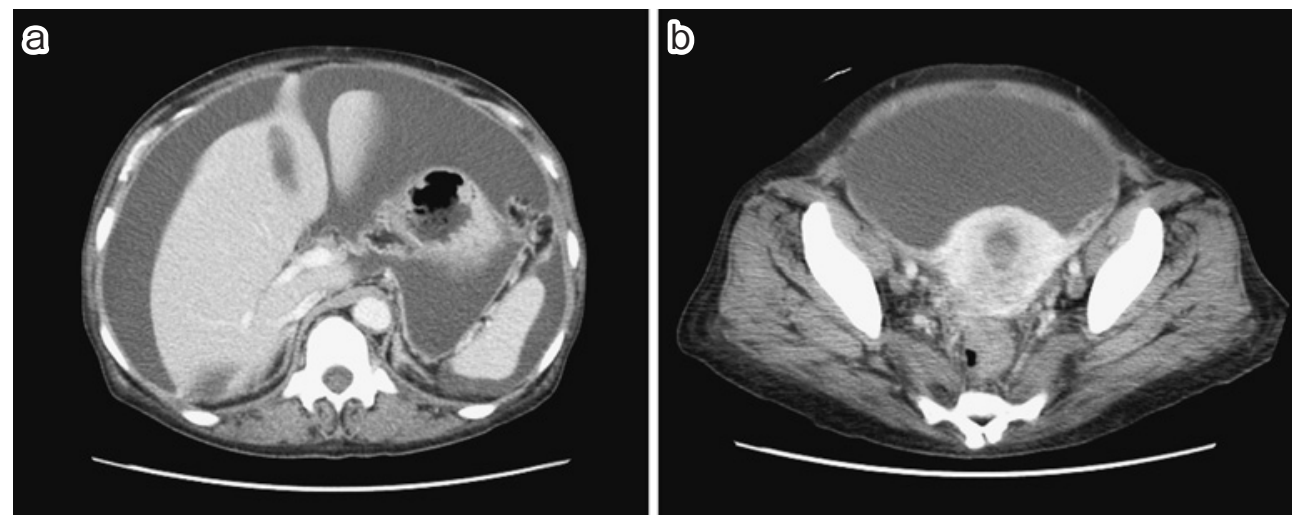

Fig. 1 Computed tomography (CT) of the abdomen (a) and pelvis (b). A large amount of ascites fluid was detected (a). The uterine wall was thickened, and the endometrial cavity was occupied by a nonenhanced lesion (b).

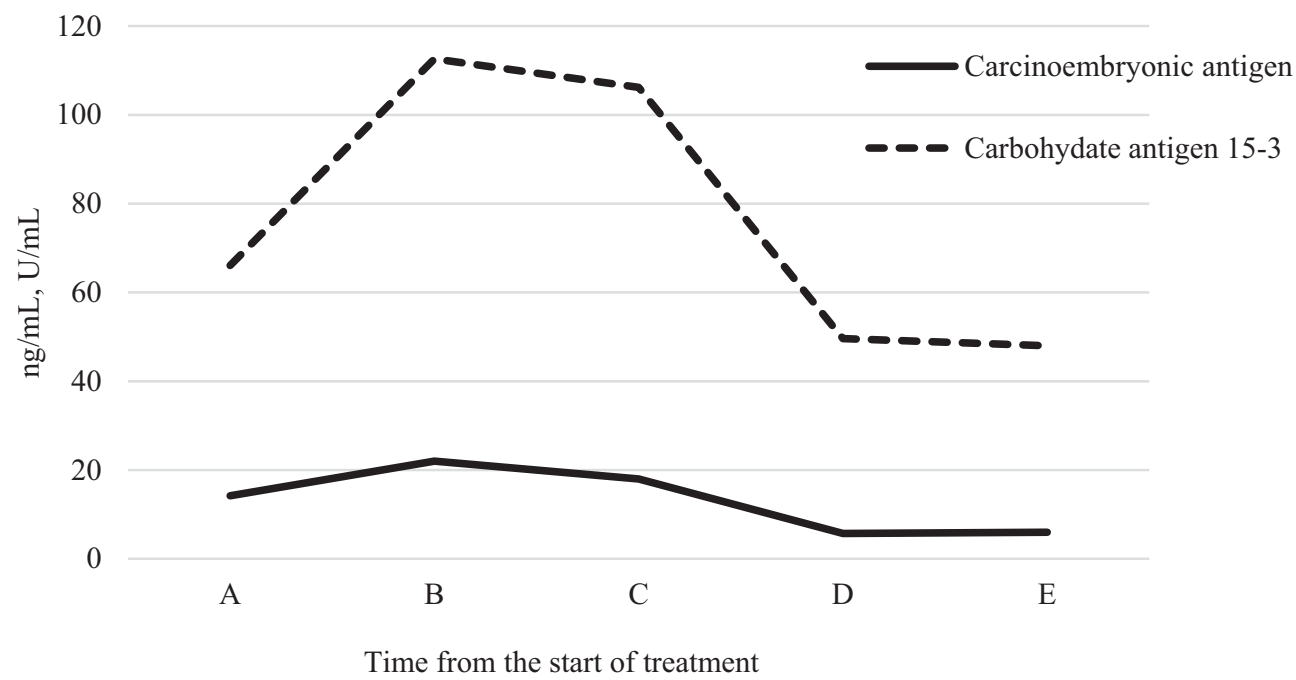

Fig. 2 Tumor makers. The concentrations of carcinoembryonic antigen (CEA) and carbohydrate antigen (CA) 15-3 were $14.2 \mathrm{ng} / \mathrm{mL}$ and $66.1 \mathrm{U} / \mathrm{mL}$, respectively, at baseline [A]. The concentrations of CEA and CA15-3 increased to $22.0 \mathrm{ng} / \mathrm{mL}$ and $112.6 \mathrm{U} / \mathrm{mL}$, respectively, at 2 months after the start of anastrozole [B]. The concentrations of CEA and CA15-3 slightly decreased to $18.0 \mathrm{ng} / \mathrm{mL}$ and $106.2 \mathrm{U} / \mathrm{mL}$, respectively, at 2 weeks after the start of combined fulvestrant with low-dose capecitabine [C]. The concentration of CEA decreased to $5.7 \mathrm{ng} / \mathrm{mL}$ at 6 months [D] and $6.0 \mathrm{ng} / \mathrm{mL}$ at 10 months [E] after the start of the combined therapy. The concentration of CA15-3 decreased to $49.6 \mathrm{U} / \mathrm{mL}$ at 6 months [D] and $48.0 \mathrm{U} / \mathrm{mL}$ at 10 months [E] after administration of the combined therapy.

tively, all of which were higher than normal ranges $(\leq 5.0$ $\mathrm{ng} / \mathrm{mL}, \leq 27.0 \mathrm{U} / \mathrm{mL},<4.5 \mathrm{U} / \mathrm{mL}$, and $\leq 35.0 \mathrm{U} / \mathrm{mL}$, respectively) (Fig. 2). Concentrations of CA19-9 and CA724 were $12.2 \mathrm{U} / \mathrm{mL}$ and $1.2 \mathrm{U} / \mathrm{mL}$, respectively, both of which were within normal ranges $(\leq 37.0 \mathrm{U} / \mathrm{mL}$ and $\leq 8.0$ $\mathrm{U} / \mathrm{mL}$, respectively). Drainage of the ascites fluid had been performed twice before the patient came to our outpatient clinic; the maximal volume of drained fluid was $4,700 \mathrm{~mL}$.

On the basis of the above findings, we concluded that the carcinoma of the left breast had metastasized to peritoneum, pleura, uterus, and bone. These metastatic patterns were considered typical of invasive lobular carcinoma of the breast.

A large amount of ascites fluid resulted in low activity in the patient's daily life; therefore, chemotherapy, such as an anthracycline or a taxane, was considered. However, the primary tumor was ER-positive and HER2negative, and the disease was not life threatening. Therefore, endocrine therapy was considered optimal as a first- 

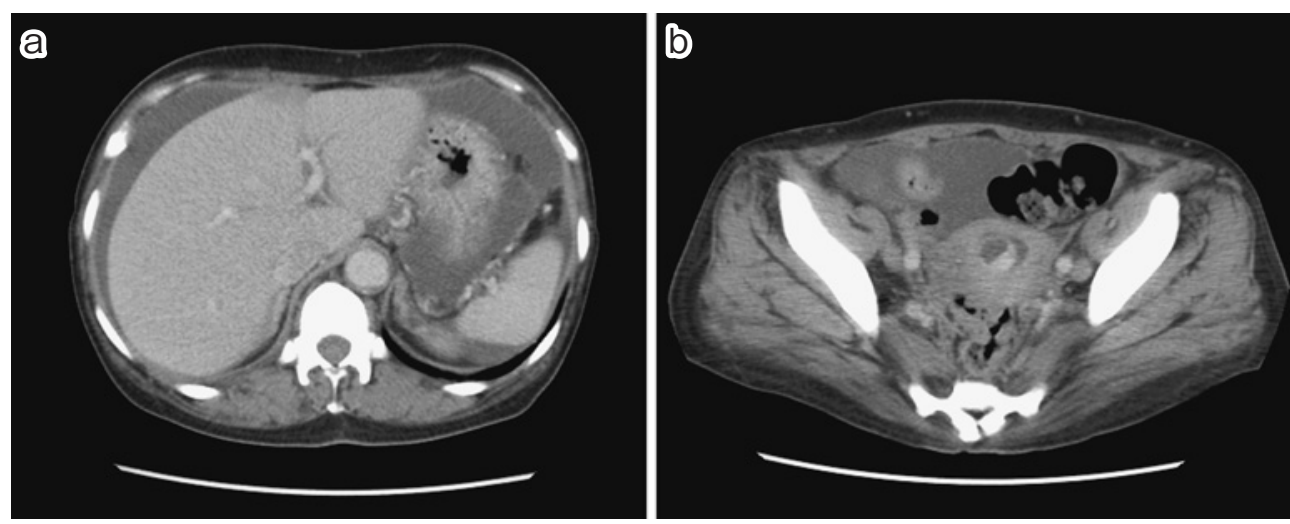

Fig. 3. Computed tomography of the abdomen (a) and pelvis (b). The ascites improved (a), and the uterine wall became thinner (b).

line therapy for the metastatic disease, accompanied by denosumab subcutaneously injected every 4 weeks. Tamoxifen or aromatase inhibitors were judged to be appropriate for this case because more than 4 years had passed since the completion of 5 years of adjuvant endocrine therapy, which had included tamoxifen and anastrozole. We chose anastrozole, which was considered to be more effective than tamoxifen. For 2 months after the start of treatment with anastrozole, the volume of the ascites had not begun to decrease. Drainage of the ascites fluid was performed 3 times during this period, and the maximal volume of drainage was $6,000 \mathrm{~mL}$. The concentrations of the tumor markers CEA and CA15-3 had increased to $22.0 \mathrm{ng} / \mathrm{mL}$ and $112.6 \mathrm{U} / \mathrm{mL}$, respectively (Fig. 2). Therefore, anastrozole was considered to have been ineffective in the present case.

As a second-line therapy, chemotherapy was considered optimal, because anastrozole had been ineffective and the ascites should have rapidly improved. However, the patient wanted to avoid hair loss. Accordingly, fulvestrant was considered suitable as a second-line endocrine therapy; however, it was not likely to rapidly decrease the volume of the ascites. Therefore, we chose to the combination of fulvestrant and capecitabine because a phase 2 trial had found that this regimen was effective and tolerable for patients with metastatic breast cancer. In this phase 2 trial, fulvestrant was administered at a low dose of $250 \mathrm{mg}$, and capecitabine was administered daily without interruption at low doses of $1,500 \mathrm{mg}$ (body weight $<80 \mathrm{~kg}$ ) and 2,000 $\mathrm{mg}$ (body weight $\geq 80 \mathrm{~kg}$ ). In the present case, $500 \mathrm{mg}$ of fulvestrant was intramuscularly injected on days 1,15 , and 29 and every 28 days thereafter. Capecitabine, $1,800 \mathrm{mg}$, was administered daily for 21 days followed by a 7-day rest period in a 28- day cycle. The daily dose of $1,500 \mathrm{mg}$ of capecitabine administered without interruption was similar to the daily dose of 2,000 $\mathrm{mg}$ of capecitabine administered for 21 days in a 28-day cycle. In Japan, capecitabine is administered only with a tablet containing $300 \mathrm{mg}$. Because our patient's body weight was approximately $48 \mathrm{~kg}, 1,800 \mathrm{mg}$ (6 tablets) of capecitabine was considered suitable.

After this combination therapy was started the patient felt slight improvement of abdominal distention, and by 2 weeks after the start the concentrations of CEA and CA $15-3$ had decreased to $18.0 \mathrm{ng} / \mathrm{mL}$ and $106.2 \mathrm{U} / \mathrm{mL}$, respectively, (Fig. 2). The ascites was drained 2 times during the month after the start of combination therapy, and the maximal volume drained was 3,500 mL. No further drainage was needed. The ascites had decreased by 10 months after the start of combination therapy (Fig. 3a), and pleural effusion had completely disappeared. Also during this time, the uterine wall became thinner (Fig. 3 b) and the endometrial cavity became smaller. Tumor markers had decreased in concentration for 10 months after the start of combined therapy (Fig. 2). No side effects were observed by physicians or complained of by the patient during the above-described period.

\section{Discussion}

In the present case, the combination of fulvestrant and low-dose capecitabine was effective and well tolerated. However, a possible question in this case is whether each drug was itself effective. A randomized phase 2 study comparing the 2 drugs as first-line endocrine therapy agents in postmenopausal women with advanced, hormone receptor-positive breast cancer showed that the median TTP was 23.4 months with 500-mg fulvestrant and 13.1 months with $1-\mathrm{mg}$ anastrozole, a $34 \%$ reduction in 
risk of progression (hazard ratio, $0.66 ; \mathrm{P}=0.01)^{12}$. A forest plot representing TTP, according to the predefined covariates, indicated that fulvestrant was significantly more effective than anastrozole in patients with no visceral involvement or prior chemotherapy ${ }^{12}$. The present patient had no visceral involvement and had not previously received chemotherapy; therefore, fulvestrant might have been more effective than anastrozole. In addition, the use of anastrozole as an adjuvant endocrine therapy might have led to resistance to anastrozole. The above suggests that fulvestrant alone might have been effective in the present case, whereas capecitabine might have had a synergistic effect.

In the present case, capecitabine was administered in a 28-day cycle at a dose of 1,800 mg (approximately 1,300 $\mathrm{mg} / \mathrm{m}^{2}$ ) per day for 21 days and was then not administered for a 7-day rest period. A Japanese capecitabine package insert lists 2 cycles of capecitabine administration for patients with advanced or recurrent breast cancer. In a 28 -day cycle $1,800,2,400$, or $3,000 \mathrm{mg}$ of capecitabine is administered daily for 21 days and then not administered for a 7-day rest period for patients with a body surface of $<1.31, \geq 1.31$ to $<1.64$, or $\geq 1.64 \mathrm{~m}^{2}$, respectively. In a 21 -day cycle $3,000,3,600,4,200$, or $4,800 \mathrm{mg}$ of capecitabine is administered daily for 14 days and then not administered for a 7-day rest period in patients with a body surface of $<1.33, \geq 1.33$ to $<1.57, \geq 1.57$ to $<1.81$, or $\geq 1.81 \mathrm{~m}^{2}$, respectively. Therefore, our patient should have received 2,400 $\mathrm{mg}$ of capecitabine daily for 21 days of the 28-day cycle because her body surface was approximately $1.4 \mathrm{~m}^{2}$. Taguchi et al. ${ }^{13}$ have reported that a capecitabine dose of $1,650 \mathrm{mg} / \mathrm{m}^{2}$ was administered for 21 days of a 28-day cycle as a first-line therapy for a patient with metastatic breast cancer that recurred after adjuvant chemotherapy with an anthracycline or a taxane. They reported a median progression-free survival of 6.9 months and a median overall survival of 24.8 months. Stockler et al. ${ }^{14}$ have reported that the following 3 treatments have the same efficacy as a first-line chemotherapy for metastatic breast cancer: $2,000 \mathrm{mg} / \mathrm{m}^{2}$ of capecitabine administered for 14 days in a 21-day cycle, $1,300 \mathrm{mg} / \mathrm{m}^{2}$ of capecitabine administered without interruption, and a classical regimen of cyclophosphamide, methotrexate, and fluorouracil. Leonard et al. $^{15}$ have reviewed clinical trials of capecitabine for metastatic breast cancer, including the studies described earlier. They concluded that the dose of capecitabine can be reduced to minimize adverse events without compromising efficacy. They recommended a starting daily dose of $2,000 \mathrm{mg} / \mathrm{m}^{2}$. Compared with these recommended or licensed setting doses, the dose of capecitabine administered to the present patient was a low 1,800 mg (approximately 1,300 mg/m²). However, the capecitabine starting dose of approximately $1,300 \mathrm{mg} / \mathrm{m}^{2}$ administered to our patient has not been clinically studied as a capecitabine monotherapy. Therefore, whether capecitabine is effective, when used alone at the dose of the present case, has not been clarified.

Schwartzberg et al. ${ }^{11}$ have performed a phase 2 trial to examine the efficacy and tolerability of fulvestrant combined with low-dose capecitabine in 41 women with hormone receptor-positive, HER2-negative metastatic breast cancer; they reported a median TTP of 26.9 months, a median overall survival of 28.7 months, a complete response rate of $4.9 \%$, a partial response rate of $19.5 \%$, a clinical benefit rate of $58.5 \%$, and a progressive disease rate of $7.3 \%$. In their study, fulvestrant was administered at an initial loading dose of $500 \mathrm{mg}$ on day 1 and then at a dose of $250 \mathrm{mg}$ on days 15 and 29 and every 28 days thereafter. Capecitabine was administered daily without interruption at a dose of either $1,500 \mathrm{mg}$ (body weight $<80 \mathrm{~kg}$ ) or $2,000 \mathrm{mg}$ (body weight $\geq 80 \mathrm{~kg}$ ). If the daily capecitabine doses are changed to adjust to our administration method, 1,500 and 2,000 mg of daily capecitabine are comparable to 2,000 and $2,667 \mathrm{mg}$, respectively. Fulvestrant was administered at a higher dose in the present case than in the above phase 2 study; whereas the daily capecitabine dose of $1,800 \mathrm{mg}$ in the present case was similar to the daily dose of 2,000 mg (body weight $<80$ $\mathrm{kg}$ ) in the phase 2 study of Schwartzberg et al. ${ }^{11}$. Therefore, our combination of fulvestrant and low-dose capecitabine might have been more effective than the regimen used in the phase 2 trial.

In the present case, no adverse events were observed for 10 months after the start of the combination therapy. Adverse events after treatment with $500 \mathrm{mg}$ of fulvestrant have been reported by Robertson et $\mathrm{al}^{12}$; with a median follow-up of 8 months the events included bone pain $(13.9 \%)$, hot flash $(12.9 \%)$, nausea $(10.9 \%)$, arthralgia $(9.9 \%)$, constipation $(9.9 \%)$, vomiting $(8.9 \%)$, dyspnea $(8.9 \%)$, injection-site pain $(5.0 \%)$, hyperhidrosis $(4.0 \%)$, and urinary tract infection $(4 \%)$. These findings suggest that fulvestrant can be safely administered with no severe side effects. In the phase 2 trial by Schwartzberg et al. of the combination of fulvestrant and low-dose capecitabine $^{11}$, the most common side effect with a median follow-up period of 11 months, which was similar to the follow-up period of 10 months of the present case, was palmar-plantar erythrodysesthesia, which was observed 
in $48.8 \%$ of patients and was followed by fatigue, $41.5 \%$; nausea, $34.1 \%$; diarrhea, $26.8 \%$; headache, $26.8 \%$; edema, $26.8 \%$; cough, $24.4 \%$; and vomiting, $24.4 \%$; however, almost all were grade 1 , according to the Common Terminology Criteria for Adverse Events, Version 3.0. These findings suggest that the additional administration of capecitabine with fulvestrant does not lead to any severe adverse events. Therefore, the combination of fulvestrant and low-dose capecitabine can be safely administered to treat metastatic breast cancer.

For the treatment of breast cancer, several molecular targeting drugs have recently been examined in combination with endocrine therapy ${ }^{3}$. One of the most suitable agents to combine with fulvestrant, as suggested by the present case study and previous studies, is low-dose capecitabine. However, the optimal dose of capecitabine, when combined with $500 \mathrm{mg}$ of fulvestrant, should be determined in future clinical trials. In conclusion, we believe that the combination of fulvestrant and low-dose capecitabine is promising, because of its efficacy and tolerability, for the treatment of patients with ER-positive, HER2-negative metastatic breast cancer.

Conflict of Interest: The authors declare no conflict of interest.

\section{References}

1. Howell A, Osborne CK, Morris C, Wakeling AE: ICI 182,780 (Faslodex): development of a novel, "pure" antiestrogen. Cancer 2000; 89: 817-825.

2. McDonnell DP, Wardell SE: The molecular mechanisms underlying the pharmacological actions of ER modulators: implications for new drug discovery in breast cancer. Curr Opin Pharmacol 2010; 10: 620-628.

3. Ciruelos E, Pascual T, Arroyo Vozmediano ML, Blanco M, Manso L, Parrilla L, Muñoz C, Vega E, Calderón MJ, Sancho B, Cortes-Funes H: The therapeutic role of fulvestrant in the management of patients with hormone receptorpositive breast cancer. Breast 2014; 23: 201-208.

4. Di Leo A, Jerusalem G, Petruzelka L, Torres R, Bondarenko IN, Khasanov R, Verhoeven D, Pedrini JL, Smirnova I, Lichinitser MR, Pendergrass K, Garnett S, Lindemann JP, Sapunar F, Martin M: Results of the CONFIRM phase III trial comparing fulvestrant $250 \mathrm{mg}$ with fulvestrant $500 \mathrm{mg}$ in postmenopausal women with estrogen receptor-positive advanced breast cancer. J Clin Oncol 2010; 28: 4594-4600.

5. Di Leo A, Jerusalem G, Petruzelka L, Torres R, Bondarenko IN, Khasanov R, Verhoeven D, Pedrini JL, Smirnova I, Lichinitser MR, Pendergrass K, Malorni L, Garnett S, Rukazenkov Y, Martin M: Final overall survival: fulves- trant $500 \mathrm{mg}$ vs $250 \mathrm{mg}$ in the randomized CONFIRM trial. J Natl Cancer Inst 2014; 106: 1-7.

6. Pritchard KI: Combining endocrine agents with chemotherapy: which patients and what sequence? Cancer 2008; 112: 718-722.

7. Noguchi S, Koyama H, Uchino J, Abe R, Miura S, Sugimachi K, Akazawa K, Abe O: Postoperative adjuvant therapy with tamoxifen, tegafur plus uracil, or both in women with node-negative breast cancer: a pooled analysis of six randomized controlled trials. J Clin Oncol 2005; 23: $2172-2184$.

8. Ikeda H, Taira N, Nogami T, Shien K, Okada M, Shien T, Doihara $\mathrm{H}$, Miyoshi S: Combination treatment with fulvestrant and various cytotoxic agents (doxorubicin, paclitaxel, docetaxel, vinorelbine, and 5-fluorouracil) has a synergistic effect in estrogen receptor-positive breast cancer. Cancer Sci 2011; 102: 2038-2042.

9. Robertson JF, Harrison M: Fulvestrant: pharmacokinetics and pharmacology. Br J Cancer 2004; 90(Suppl 1): S7-S10.

10. Schroth W, Goetz MP, Hamann U, Fasching PA, Schmidt M, Winter S, Fritz P, Simon W, Suman VJ, Ames MM, Safgren SL, Kuffel MJ, Ulmer HU, Boländer J, Strick R, Beckmann MW, Koelbl H, Weinshilboum RM, Ingle JN, Eichelbaum M, Schwab M, Brauch H: Association between CYP2D6 polymorphisms and outcomes among women with early stage breast cancer treated with tamoxifen. JAMA 2009; 302: 1429-1436.

11. Schwartzberg LS, Wang G, Somer BG, Blakely LJ, Wheeler BM, Walker MS, Stepanski EJ, Houts AC: Phase II trial of fulvestrant with metronomic capecitabine for postmenopausal women with hormone receptor-positive, HER2-negative metastatic breast cancer. Clinical Breast Cancer 2014; 14: 13-19.

12. Robertson JF, Lindemann JP, Llombart-Cussac A, Rolski J, Feltl D, Dewar J, Emerson L, Dean A, Ellis MJ: Fulvestrant $500 \mathrm{mg}$ versus anastrozole $1 \mathrm{mg}$ for the first-line treatment of advanced breast cancer: follow-up analysis from the randomized 'FIRST' study. Breast Cancer Res Treat 2012; 136: 503-511.

13. Taguchi T, Nakayama T, Masuda N, Yoshidome K, Akagi K, Nishida Y, Yoshikawa Y, Ogino N, Abe C, Sakamoto J, Noguchi S: Kinki Breast Cancer Study Group: Study of low-dose capecitabine monotherapy for metastatic breast cancer. Chemotherapy 2010; 56: 166-170.

14. Stockler MR, Harvey VJ, Francis PA, Byrne MJ, Ackland SP, Fitzharris B, Van Hazel G, Wilcken NR, Grimison PS, Nowak AK, Gainford MC, Fong A, Paksec L, Sourjina T, Zannino D, Gebski V, Simes RJ, Forbes JF, Coates AS: Capecitabine versus classical cyclophosphamide, methotrexate, and fluorouracil as first-line chemotherapy for advanced breast cancer. J Clin Oncol 2011; 29: 4498-4504.

15. Leonard R, Hennessy BT, Blum JL, O'Shaughnessy J: Dose-adjusting capecitabine minimizes adverse effects while maintaining efficacy: a retrospective review of capecitabine for metastatic breast cancer. Clin Breast Cancer 2011; 11: 349-356. 